\title{
INCIDENCE OF CRIME UNDER THE INFLUENCE OF ALCOHOL INTOXICATION IN LAHORE
}

\author{
Shagufta Shafi ${ }^{1}$, Muhammad Yousaf ${ }^{2}$, Rizwan Zafar Ansari ${ }^{3}$, Anwar UI Haq $^{3}$, Zahid Hussain \\ $\mathrm{Khalil}^{4}$, Riaz Gul ${ }^{3}$ \\ 1. International Medical College \\ 2. Khyber Medical College \\ 3. Northwest School of Medicine \\ 4. Kabir Medical College
}

\section{ABSTRACT:}

\section{OBJECTIVE:}

To determine the crimes committed under the influence of alcohol in district Lahore.

\section{METHODOLOGY:}

A six months study of alcohol intoxication through cases brought for examination at office of surgeon medicolegal Lahore from January 01, 2016 to June 30, 2016 is conducted. Available data is analyzed on SPSS 13 which includes variables of age, gender, socio-economic conditions, religious background, and time of the day when the case brought for examination.

\section{RESULTS:}

Maximum number of cases is of $3^{\text {rd }}$ decade of life i.e. 21-30 year of age. Consumption of alcohol is found highest in younger age group (21-30 years) i.e. 57.6\%, while minimum consumption is observed i.e. $4 \%$ and $4.1 \%$ respectively in the age group of 51-60 years and 61-70 years. The cases which were males, Muslims and brought at day time, formed a larger group which outnumbered the females, nonMuslims and night cases.

\section{CONCLUSION:}

The study indicated that rate of crime incidence under alcohol consumption was significantly high in Muslim males. The facts highlighted by the study are significant and may be helpful to policy makers and law enforcing authorities in the city of Lahore for the years to come.

KEYWORDS: Alcohol, Intoxication, Drunkenness, Clinical Examination, Chemical Examination

\section{INTRODUCTION:}

Increasing consumption of alcohol in the modern

\begin{tabular}{|c|}
\hline Correspondence \\
Rizwan Zafar Ansari \\
Forensic Medicine \& Toxicology \\
Northwest School of Medicine \\
Email: dr.rizwan@nwsm.edu.pk \\
Phone: 0324-4055667 \\
\hline https://doi.org/10.37762/jgmds.5-1.13
\end{tabular}
society is well documented and is taken as country's economic and social development $^{1}$. The toxicity of beverage alcohol is well known. Acute toxicity correlates fairly well with dose and blood level ${ }^{2}$. Alcohol is a generic term for ethanol, which is a peculiar type of beverage produced by fermentation of many food stuffs such as barley, hops and grapes ${ }^{3}$. Other types of alcohol commonly available are methanol; isopropyl alcohol and ethylene glycol are highly poisonous when swallowed even in small 
quantities ${ }^{4}$. Ethanol is the alcohol constituent of beverages and is most commonly abused intoxicant ${ }^{5}$. It is very frequently involved in clinical poisoning often in combination with therapeutic agents $^{6}$. A person is said to suffer from alcohol intoxication when the quantity of alcohol a person consumes exceeds the individual tolerance for alcohol and produces behavioral and physical abnormalities. In other words, the person's mental and physical abilities are impaired ${ }^{7}$. In Western civilization the recent upsurge in alcoholism, particularly in younger generation has received much publicity and has currently given rise to much medical and sociological concern ${ }^{8}$. Like all big cities, Lahore cannot be excluded, where cases of drunkenness are commonly reported and brought for medicolegal certification. An effort has been made to study the trends for alcohol intake in the city.

\section{METHODOLOGY:}

Up to the year 2016 surgeon medicolegal office located in Anarkali Lahore was the biggest center catering cases for medicolegal certification. In the first 6 month of the same year, 1002 cases of alcohol intoxication were brought for examination and certification. The available data of cases is analyzed on the basis of variables like age, gender, socio-economic conditions, religion, and time of day, monthly load of cases, area police station and chemical examiner report. The cases were examined by the medical officers working in the surgeon medicolegal office. The analysis is without any prejudice depending only on the available data.

\section{RESULTS:}

Most of offenders were caught soon after commission of crime 943 (94.2\%). 877 (87.8\%) crime happened during day including 521 road traffic accidents, 134 robbery cases, 76 incidents of purse snatching, 56 incidents of harassing females standing on bus stands and 90 cases of stealing eatables from road side shops as illustrated in Figure 1. Consumption of alcohol was found highest in younger age group (21-30 years) i.e. $577 \quad(57.6 \%)$, while minimum consumption is observed i.e. $4 \%$ and $4.1 \%$ respectively in the age group of 51-60 years and 61-70 years. Gender differences shows that maximum usage by male group is $98.9 \%$ while for females it is only $1.1 \%$. Socio-economic pattern of beverage use depicted that labor and unemployed group to be at the peak i.e. $38.5 \%$, followed by businessman $33 \%$, educated community $19.1 \%$ while government servants are the least users i.e. $9.6 \%$. Religious charting reveals that Muslims have clearly outnumbered the non-Muslims; $90 \%$ and $10 \%$ respectively. Daily clock monitoring is laid down in Table 2 where day time drinkers have left behind the night time users i.e. $60 \%$ and $40 \%$. The calendar highlights February to be at the top and June at the bottom. Table 3 displays the comparison of clinical assessment and chemical analysis. According to clinical assessment $88.8 \%$ cases are positive for beverage use while $11.2 \%$ were negative on clinical examination. On the contrary chemical analysis proved $63.9 \%$ as positive for alcohol use, $1.2 \%$ as negative, while no report issued in $35 \%$ cases. Table 4 indicating area police station manifested Shaahdrah to be highest i.e. $7.1 \%$ while Johar Town to be the lowest i.e. $0.3 \%$.

Table 1: Demographics of Respondents

\begin{tabular}{|c|c|c|c|}
\hline Characteristics & Category & Cases & Percentage \\
\hline Age & $0-10$ & 0 & 0 \\
\hline \multirow{3}{*}{} & $11-20$ & 96 & 9.6 \\
\cline { 2 - 4 } & $21-30$ & 576 & 57.6 \\
\hline
\end{tabular}


Table 1: Demographics of Respondents (Continued)

\begin{tabular}{|c|c|c|c|}
\hline Characteristics & Category & Cases & Percentage \\
\hline \multirow{4}{*}{ Gender } & $31-40$ & 192 & 19.2 \\
\cline { 2 - 4 } & $41-50$ & 57 & 5.7 \\
\cline { 2 - 4 } & $51-60$ & 40 & 4 \\
\cline { 2 - 4 } & $61-70$ & 41 & 4.1 \\
\cline { 2 - 4 } & Total & 1002 & 100 \\
\hline \multirow{5}{*}{ Class } & Male & 989 & 98.9 \\
\hline \multirow{4}{*}{ Religion } & Female & 13 & 1.1 \\
\cline { 2 - 4 } & Total & 1002 & 100 \\
\cline { 2 - 4 } & Labor/Unemployed & 385 & 38.5 \\
\cline { 2 - 4 } & Businessman & 330 & 33 \\
\cline { 2 - 4 } & Educated & 191 & 19.1 \\
\cline { 2 - 4 } & Government Employed & 96 & 9.6 \\
\cline { 2 - 4 } & Total & 1002 & 100 \\
\cline { 2 - 4 } & Muslims & 900 & 102 \\
\hline \multirow{4}{*}{} & Non-Muslims & 1002 & 100 \\
\hline
\end{tabular}

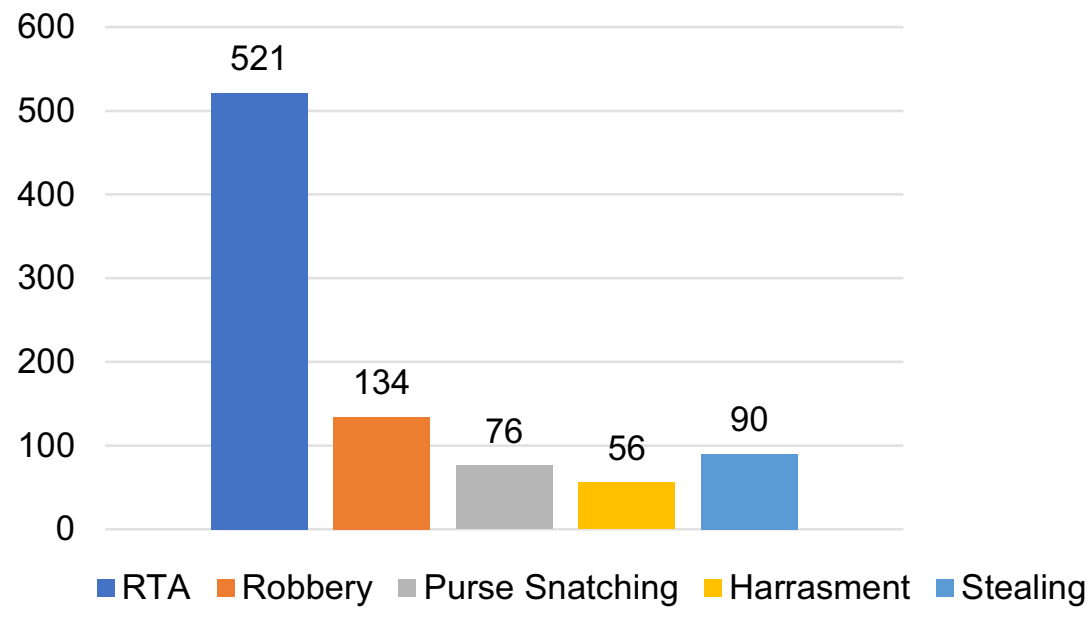

Figure 1: No of Cases 
Table 2: Timing of Consumption

\begin{tabular}{|c|c|c|c|}
\hline Characteristics & Category & Cases & Percentage \\
\hline \multirow{4}{*}{$\begin{array}{c}\text { Time of } \\
\text { Commission of } \\
\text { Crime }\end{array}$} & Night & 400 & 40 \\
\cline { 2 - 4 } & Day & 602 & 60 \\
\cline { 2 - 4 } & Total & 1002 & 100 \\
\cline { 2 - 4 } & January & 182 & 18 \\
\cline { 2 - 4 } & February & 222 & 22 \\
\cline { 2 - 4 } & March & 166 & 17 \\
\cline { 2 - 4 } & April & 165 & 16 \\
\cline { 2 - 4 } & May & 139 & 14 \\
\cline { 2 - 4 } & June & 128 & 100 \\
\hline
\end{tabular}

Table 3: Doctor and Chemical Examiner Assessment

\begin{tabular}{|c|c|c|c|}
\hline Assessment & Results & Cases & Percentage \\
\hline Doctors Assessment as Clinical & Positive & 888 & 88.8 \\
Examiner & Negative & 114 & 11.2 \\
\hline \multirow{2}{*}{ Chemical Examiners Report } & Positive & 639 & 63.9 \\
& Negative & 12 & 1.2 \\
& Undeclared & 351 & 35 \\
\hline
\end{tabular}

Table 4: Area Police Station

\begin{tabular}{|c|c|c|}
\hline Police Station & Cases & Percentage \\
\hline Shaahdrah & 71 & 7.1 \\
\hline Hurbanspura & 59 & 5.9 \\
\hline Johar Town & 3 & 0.3 \\
\hline
\end{tabular}

\section{DISCUSSION:}

The most widely used drug in the world is ethanol which accounts for huge morbidity and mortality, because of its contribution to accidents and as catalyst in the majority of assaults and homicides. Even in those countries where religious beliefs theoretically prevent the consumption of alcohol, it is still in wide spread use ${ }^{9}$. Table 1 proves that in spite of all sanctions in Pakistan on the use of alcohol, Muslim users are in huge number $(90 \%)$ as compared to $10 \%$ non-Muslims. Like religious sanction on use of alcohol, some ethnic communities do not like using alcohol as drug point, so we find very low rates of alcoholism among the Chinese and Jewish people while there are very high rates among Irish and American Indian people ${ }^{10}$. The details on the basis of ethnic group consumptions is beyond the scope of the study however a separate study can be conducted to know further details. Drinking is often learned among peers in a surreptitious manner during mid or late adolescence, often in context when the same individuals are learning adult social roles and sexual relationship with the opposite sex ${ }^{11}$.The findings in Table 1, 21-30 years as the age of maximum involvement i.e. $57.6 \%$ coincides with the fact. Drinking may be formally or ideally viewed as a socially undesirable activity and for many decades it was 
thought that the person prone to alcoholism was to use Freudian terms an "oral personality"12. This term refers to an individual who lean on others and have little self direction ${ }^{13}$. Table1 depicting socioeconomic pattern coincide with the similar facts. Yeast driven fermentation of sugars resulting in production of ethanol which is found at various concentration in different drinks ${ }^{14}$. Although the number and type of drinks ingested over a given period of time can be used to estimate alcohol concentration in blood and brain, many factors determine how fast the alcohol is absorbed and what degree of impairment results from it. These factors include the presence of food in stomach, gender and weight of individual, and rate of elimination ${ }^{15}$. Studies have shown effect of age and gender on rate of elimination of ethanol from the body. In a study of ethanol elimination of the suspects, the mean elimination rate for females was significantly higher than males. Studies have also shown the difference in body weight and persons age effecting the elimination of alcohol from the body ${ }^{14-15}$. In practice high dose consumers will have a higher elimination rate that can reduce the detection time while retention of alcohol in the bladder is likely to increase the detection time for a few hours. Likewise, many other factors influencing the alcohol consumers can be studied by further elaborating such studies. Findings of Table 2, 3 and 4 cannot be much commented upon however larger gaps in the findings of clinical examination and chemical examination should be tried to overcome so that the validity and authenticity of reports of both examinations is established.

\section{CONCLUSION:}

The study indicated that rate of crime incidence under alcohol consumption was significantly high in Muslim males. Large number of unemployed persons using alcohol is also an alarming sign and some steps to reduce unemployment may reduce alcohol consumption. Control on alcohol use may also affect the control of violence in the community. Restriction on use of alcohol specially during driving should be enhanced further. Researchers and academicians can use this study in different modified form to draw conclusion on different aspect of use and effect of alcohol.

\section{REFERENCES:}

1. Haider W, Chaudhry MA. Prevalence of alcoholism in the Punjab, Pakistan. Biomedica. 2008;24:80-4.

2. Greenfeld LA. Alcohol and crime: an analysis of national data on the prevalence of alcohol involvement in crime. 1998;1-47.

3. Mirza FH, Arif K. Acute alcohol intoxication: prevalence, recognition and medicolegal importance. J Pak Med Assoc. 1999;49(9):220-21.

4. Leigh BC. Peril, chance, adventure: concepts of risk, alcohol use and risky behavior in young adults. Addiction. 1999;94(3):371-83.

5. Waller PF, Stewart JR, Hansen AR, Stutts JC, Popkin CL, Rodgman EA. The potentiating effects of alcohol on driver injury. JAMA. 1986;256(11):1461-66.

6. Greenfield TK, Weisner C. Drinking problems and self-reported criminal behavior, arrests and convictions: 1990 US alcohol and 1989 county surveys. Addiction. 1995;90(3):36173.

7. Chandra PS, Krishna VA, Benegal V, Ramakrishna J. High-risk sexual behavior and sensation seeking among heavy alcohol users. Indian J Med Res. 2003;117:88-92.

8. Lapham SC, Smith E, C'de Baca J, Chang I, Skipper BJ, Baum G, Hunt WC. Prevalence of psychiatric disorders among persons convicted of driving while impaired. Archives Gen Psychiatry. 2001;58(10):943-49.

9. Fine EW, Scoles P, Mulligan M. Under the influence: characteristics and drinking practices of persons arrested for the first time for drunk driving, with treatment implications. Public Health Report. 1975;90:424-29 
10. Thompson MP, Kingree JB. The roles of victim and perpetrator alcohol use in intimate partner violence outcomes. J Interpersonal Violence. 2006;21(2):163-77.

11. Macdonald S, Pederson LL. Occurrence and patterns of driving behavior for alcoholics in treatment. Drug Alcohol Dependence. 1988;22(1):15-25.

12. Vijayanath V, Tarachand KC. Alcohol and crime behavior. Indian Academy Forensic Med. 2011;33(3).

13. Gupta PC, Saxena S, Pednekar MS, Maulik PK. Alcohol consumption among middle-aged and elderly men: a community study from western India. Alcohol \& Alcoholism. 2003;38(4):327-31.

14. Chaudhary V, Katyal R, Singh SP, Joshi HS, Upadhyay D, Singh A. A study on pattern of alcohol use using audit among the college students in a medical college of north India. National J Community Med. 2015;6(2):25357.

15. Mbatia J, Jenkins R, Singleton N, White B. Prevalence of alcohol consumption and hazardous drinking, tobacco and drug use in urban Tanzania, and their associated risk factors. Int J Environ Res Public Health. 2009;6(7):1991-2006.

LICENSE: JGMDS publishes its articles under a Creative Commons Attribution Non-Commercial Share-Alike license (CC-BY-NC-SA 4 COPYRIGHTS: Authors retain the rights without any restrictions to freely download, print, share and disseminate the article for any lawful purpose. It includes scholarly networks such as Research Gate, Google Scholar, LinkedIn, Academia.edu, Twitter, and other academic or professional networking sites. 